\title{
Epidermal Inclusion Cyst of the Breast
}

\author{
Keywords: Epidermal inclusion cyst; Fibroadenoma; Excision biopsy \\ Abstract \\ Epidermal inclusion cysts are uncommon in the breast, but the \\ consequences can be severe when these cysts occur in the breast \\ parenchyma. Here we report one such case. \\ The patient was 45 years old women with $3^{*} 2 \mathrm{cms}$ mobile lump in \\ lower outer quadrant of left breast and another $3^{*} 1 \mathrm{cms}$ mobile lump in \\ central quadrant of right breast. Mammography showed well defined \\ oval shaped mass in both the breast suggestive of fibroadenoma of \\ bilateral breast. FNAC was done and showed features of epidermal \\ inclusion cyst in left breast and fibroadenoma of right breast. The \\ excision biopsy confirmed the same diagnosis.
}

\section{Introduction}

An epidermal inclusion cyst is lined by a cornified epithelium, has a distinct granular layer, and contains lamellated keratin without calcification. Such cysts most commonly occur on the scalp and in the skin of the neck and back, whereas they are only rarely found in other areas, including the skin of the breast.

Diagnosis is straightforward for epidermal inclusion cysts that occur in the breast sub cutis as a small nodule, but enlarged cysts presenting in the breast parenchyma require them to be differentiated from malignant or benign tumors of the breast. Here we presenting a case of epidermal inclusion cyst of the breast.

\section{Case Report}

The patient was 40 years female came to the outpatient department with complaining of lump in bilateral breast since one year there was no history of increase in size of the lumps and secondary changes. On clinical examination there was $3^{*} 2 \mathrm{cms}$ mobile lump in lower outer quadrant of left breast and another $3^{*} 1 \mathrm{cms}$ mobile lump in central quadrant of right breast detected. Bilateral breast mammography showed well defined oval shaped mass in both the breast suggestive of fibroadenoma, and FNAC was done showed the features suggestive of fibroadenoma of right breast and epidermal inclusion cyst of left breast. The excision biopsy was done to confirm the diagnosis showed the similar findings.

\section{Discussion}

Epidermal cysts in the breast are believed to arise through several different mechanisms. First, they can develop from obstructed hair follicles. Second, they may result from trauma, such as that due to reduction mammoplasty or needle biopsy of the breast, which may cause torn fragments of the epidermis to become implanted deep within the breast tissue [1-3]. Third, they can be created by squamous metaplasia of normal columnar cells within an ectatic duct in an area of fibrocystic disease or in a fibroadenoma [4]. In our case the pathogenesis of the epidermal inclusion cysts may have been obstruction of hair follicles, because there was no past history of breast biopsy or trauma.

\section{Journal of Surgery}

\section{Raghupathi S*, Suma S, Prakash and Sreeramulu PN}

Department of general surgery, Sri Devaraj Urs Academy of Higher Education and Research, India

*Address for Correspondence

Raghupathi S, Department of general surgery, Sri Devaraj Urs Academy of Higher Education and Research, Kolar, India; E-mail: drraghupathibmcri@gmail.com

Submission: 20 February, 2017

Accepted: 01 April, 2017

Published: 06 April, 2017

Copyright: () 2017 Raghupathi S, et al. This is an open access article distributed under the Creative Commons Attribution License, which permits unrestricted use, distribution, and reproduction in any medium, provided the original work is properly cited.

Generally, epidermal inclusion cysts that develop in the skin of the head and dorsal region are macroscopically noted as protrusions from the skin, which may be due to the firm composition of subcutaneous tissue such as bone and muscle in the head and dorsal region. On the other hand, histologically flexible fat and mammary gland tissues are present under the breast skin, and this may explain why epidermal inclusion cysts that develop in the breast skin grow toward the deep subcutaneous tissue and are difficult to distinguish clinically from a mammary gland tumor [1-3]. On mammography, an epidermal inclusion cyst appears as a well-circumscribed, homogeneous density and thus is distinguishable from breast cancer [5]. Even when the mammographic appearance of a palpable mass is consistent with a benign lesion, the finding of a solid lesion on sonography may require tissue diagnosis to exclude a carcinoma with well-defined borders, as in our Case on sonography, breast epidermal inclusion cysts have a solid, well-circumscribed and complex appearance; the specific sonographic features of these cysts were described by Pavel et al. as an onion-ring appearance with alternating concentric hyperechoic and hypoechoic rings, which correspond to the pathologic features of lamellated keratin [6].

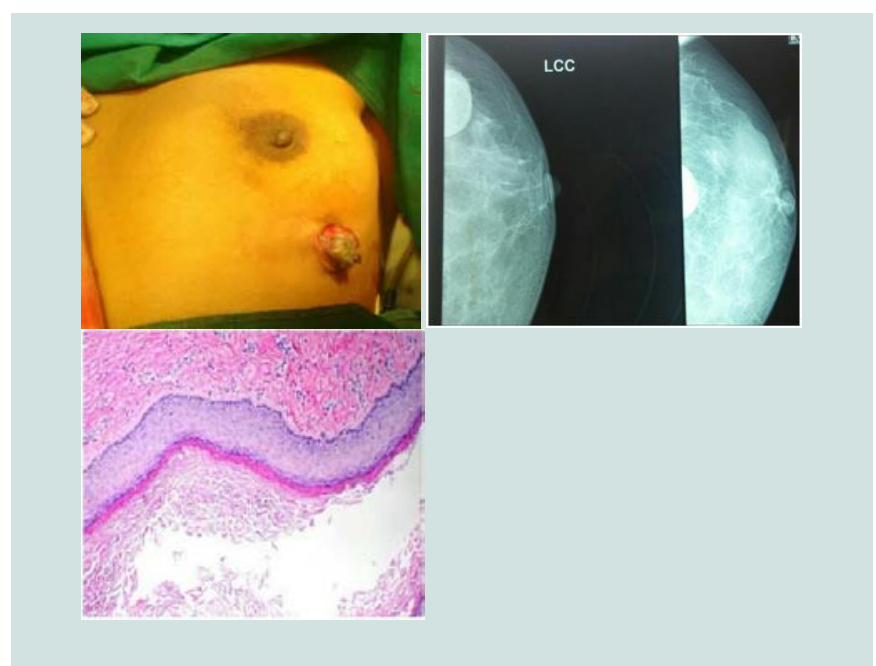


Although epidermal inclusion cysts are benign, occasionally they may play a role in the origin of squamous carcinoma of the breast. Squamous cell carcinoma develops only rarely $(0.045 \%)$ in the wall of common epidermal inclusion cysts [7].

\section{Conclusion}

In summary, an epidermal inclusion cyst of the breast is potentially serious, although such cysts are rare, and differentiation from a malignant or benign breast tumor is required. Excision is probably the most appropriate treatment, and this removes the possible risk of malignant transformation.

\section{References}

1. Gerlock AJ (1974) Epidermal inclusion cyst of the breast associated with needle aspiration biopsy. Radiology 112: 69-70.

2. Davies JD, Nonni A, D'Costa HF (1997) Mammary epidermoid inclusion cysts after wide-core needle biopsies. Histopathology 31: 549-551.

3. Fajardo LL, Bessen SC (1993) Epidermal inclusion cyst after reduction mammoplasty. Radiology 186: 103-106.

4. Chantra PK, Tnag JT, Stanley TM, Bassett LW (1994) Circumscribed fibrocystic mastopathy with formation of an epidermal cyst. AJR Am J Roentgenol 163: 831-832.

5. Morris PC, Cawson JN, Balasubramaniam GS (1999) Epidermal cyst of the breast: detection in a screening programme. Australas Radiol 143: 12-15.

6. Crystal P, Shaco-Levy R (2005) Concentric rings within abreast mass on sonography: lamellated keratin in an epidermal inclusion cyst. AJR Am J Roentgenol 184(3 Suppl): S47-S48.

7. Cameron DS, Hilsinger RL Jr (2003) Squamous cell carcinoma in an epidermal inclusion cyst: case report. Otolaryngol Head Neck Surg 129: 141143. 